\title{
Epitranscriptomic regulation of transcriptome plasticity in development and diseases of the brain
}

\author{
Chan-Woo Park, Sung-Min Lee \& Ki-Jun Yoon * \\ Department of Biological Sciences, Korea Advanced Institute of Science and Technology (KAIST), Daejeon 34141, Korea
}

\begin{abstract}
Proper development of the nervous system is critical for its function, and deficits in neural development have been implicated in many brain disorders. A precise and predictable developmental schedule requires highly coordinated gene expression programs that orchestrate the dynamics of the developing brain. Especially, recent discoveries have been showing that various mRNA chemical modifications can affect RNA metabolism including decay, transport, splicing, and translation in cell typeand tissue-specific manner, leading to the emergence of the field of epitranscriptomics. Moreover, accumulating evidences showed that certain types of RNA modifications are predominantly found in the developing brain and their dysregulation disrupts not only the developmental processes, but also neuronal activities, suggesting that epitranscriptomic mechanisms play critical post-transcriptional regulatory roles in development of the brain and etiology of brain disorders. Here, we review recent advances in our understanding of molecular regulation on transcriptome plasticity by RNA modifications in neurodevelopment and how alterations in these RNA regulatory programs lead to human brain disorders. [BMB Reports 2020; 53(11): 551-564]
\end{abstract}

\section{INTRODUCTION}

During development of the central nervous system (CNS), a wide variety of unique cell types are generated with temporal and spatial precision. In the early embryo, neural stem cells sequentially produce neurons and glial cells that orderly migrate to assemble into neural circuits (1). These processes are accurately curated by dynamic gene expression programs that guide the patterning of the differentiation potential of progenitors and the divergence of neuronal/glial lineages. Epigenetic mechanisms, such as DNA methylation, histone modification, and changes

*Corresponding author. Tel: +82-42-350-2628; Fax: +82-42-350-2610; E-mail: kijunyoon@kaist.ac.kr

https://doi.org/10.5483/BMBRep.2020.53.11.204

Received 2 September 2020

Keywords: Brain disorders, Epitranscriptome, Neurodevelopment, RNA modification, Transcriptome plasticity in chromatin architecture, have been extensively investigated in neural development over the last decades (2). In addition, post-transcriptional regulation mediated by chemical modification on RNA provides an additional control of fine-tuned gene expression patterns requiring for the proper development and activity of the nervous system (3). Especially, the advance of high-throughput sequencing approaches and quantitative mass spectrometric analysis revealed the existence of more than 160 types of RNA modifications, including N6-methyladenosine $\left(m^{6} A\right)$, 5-methylcytosine $\left(m^{5} \mathrm{C}\right)$, pseudouridine $(\psi), \quad N 6,2^{\prime}-\mathrm{O}-$ dimethyladenosine $\left(\mathrm{m}^{6} \mathrm{Am}\right), \mathrm{N} 1$-methyladenosine $\left(\mathrm{m}^{1} \mathrm{~A}\right)$ and N4-acetylcytidine $\left(\mathrm{ac}^{4} \mathrm{C}\right)(4,5)$. Different RNA species, such as transfer RNAs (tRNAs), ribosomal RNAs (rRNAs), messenger RNAs (mRNAs), and non-coding RNAs (ncRNAs) are often post-transcriptionally modified by chemical modifications.

The transcriptomic plasticity, conferred by post-transcriptional regulation including RNA modification, editing, and alternative splicing, is recognized as a fundamental mechanism driving proteomic diversity (6). Notably, recent studies suggested that RNA modifications influence almost all aspects of RNA metabolism, including stability, splicing, localization, and translation. These regulations by RNA modifications have physiologically important functions in many different biological contexts in cell- and/or tissue type-specific manners, eventually opening a newly emerging field, known as the epitranscriptomics.

Several epitranscriptome mapping studies showed that the embryonic and adult tissues that build up the mammalian CNS contain relatively higher abundance of RNA modifications than other organs. For example, higher level of $\mathrm{m}^{6} \mathrm{~A}$ and $\mathrm{m}^{6} \mathrm{Am}$ in mRNA exist both in human and mouse brain tissues compared to non-brain tissues $(7,8)$, and it was also reported that either $\mathrm{m}^{5} \mathrm{C}$ or $\psi$ level was significantly higher in the brain than those in other tissues $(9,10)$. These results imply that fine-tuning of gene expression by RNA modifications may regulate development and function of the CNS. Therefore, dysregulation of these post-translational regulatory programs often manifests as malformation or dysfunction of the normal CNS, which is implanted in various human brain disorders. In this review, we will overview the recent advances in our understanding of the transcriptome plasticity by RNA modifications in neurodevelopment, and how the alterations in these RNA regulatory programs lead to human brain disorders.

ISSN: 1976-670X (electronic edition)

Copyright (c) 2020 by the The Korean Society for Biochemistry and Molecular Biology

(ㄷ) This is an open-access article distributed under the terms of the Creative Commons Attribution Non-Commercial License (http://creativecommons.org/licenses/by-nc/4.0) which permits unrestricted non-commercial use, distribution, and reproduction in any medium, provided the original work is properly cited. 


\section{REGULATORY MACHINERIES OF THE EPITRANSCRIPTOME: WRITERS, ERASERS AND READERS}

RNA modifications are tightly regulated by specialized RNAbinding proteins. Similar to epigenetic regulatory proteins, epitranscriptomic "writers" catalyze the installation of chemical modifications on RNA, "erasers" reverse the modified chemical groups into the original form, and "readers" recognize the modified RNAs to affect various aspects of RNA metabolism (Fig. 1).

First of all, we will discuss the major epitranscriptomic marks predominantly found in the CNS and their regulatory machineries, and then focus on recent progress to highlight the physiological roles of epitranscriptome in development and disorders of the nervous system.

\section{N6-methyladenosine $\left(m^{6} A\right)$}

$\mathrm{m}^{6} \mathrm{~A}$ is the most abundant internal modification in mRNA and noncoding RNA, that affects various aspects of RNA metabolism, including stability, splicing, translation, localization, and

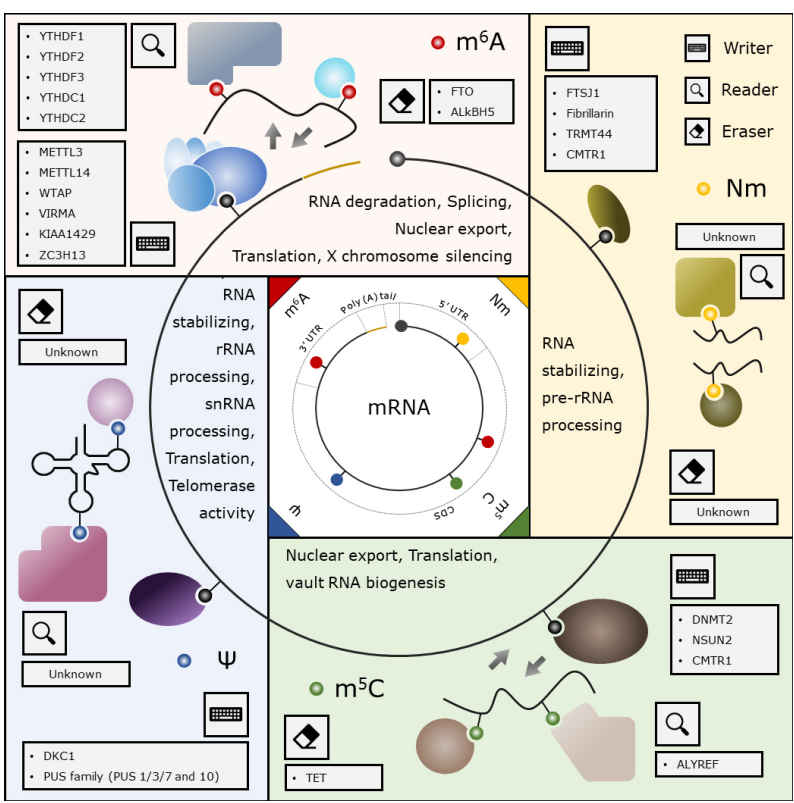

Fig. 1. The Epitranscriptomic machinery and its regulatory function in eukaryotes. Eukaryotic RNA modifications, including $\mathrm{m}^{6} \mathrm{~A}, \mathrm{Nm}$, $\mathrm{m}^{5} \mathrm{C}$ and $\psi$ (depicted clock-wisely in this board from top left) can be installed, read and removed by specialized proteins known as writer (marked with a keyboard), reader (marked with a magnifier) and eraser proteins (marked with a rubber), respectively. The dynamic alteration of transcriptome plasticity conferred by each of RNA modifications includes RNA degradation, splicing nuclear export, translation, as well as the processing of non-coding RNAs. Each RNA modification is illustrated in a pin with different colors: $\mathrm{m}^{6} \mathrm{~A}$ - red, $\mathrm{Nm}$ - yellow, $\mathrm{m}^{5} \mathrm{C}$ - green, and $\psi$ - blue, respectively. biogenesis of specific small regulatory RNAs $(4,5)$. Genomewide mapping studies showed that $\mathrm{m}^{6} \mathrm{~A}$ modification generally prefers to be installed at the DRACH $(\mathrm{D}=\mathrm{A}, \mathrm{U}$ or $\mathrm{G}$; $\mathrm{R}=$ Purine; $\mathrm{H}=\mathrm{A}, \mathrm{U}$ or $\mathrm{C}$ ) consensus sequence, and is highly enriched either in the 3' UTR around stop codons and long exons $(7,11)$, though sometimes it can be also found in $5^{\prime}$ UTR region with lesser levels (12). The $\mathrm{m}^{6} \mathrm{~A}$ modification is catalyzed by a core methyltransferase complex which is composed of two heterodimeric subunits, corresponding to Methyltransferase like-3 (METTL3) and Methyltransferase like-14 (METTL 14), both of which are essential for precise action of the complex (13). Furthermore, other regulatory proteins, including Wilms tumor 1-associating protein (WTAP), Vir like $\mathrm{m}^{6} \mathrm{~A}$ methyltransferase associated (VIRMA), KIAA1429, zinc finger $\mathrm{CCCH}$ type containing $13(\mathrm{ZC} 3 \mathrm{H} 13)$, and RNA binding motif protein 14 (RBM14/14B) interact with core METTL3-METTL14 complex to contribute to RNA binding specificity and nuclear localization of the core complex (5). On the other hand, two major $\mathrm{Fe}^{2+}-\alpha$-ketoglutarate-dependent $\mathrm{m}^{6} \mathrm{~A}$ demethylases, Fat mass and obesity-associated protein (FTO) and alkB homolog 5 $(\mathrm{ALKBH} 5)$ are known for their function in erasing $\mathrm{m}^{6} \mathrm{~A}$ marks from target RNAs $(14,15)$, although the substrate preference of FTO is still controversial due to its demethylase activity either to internal $\mathrm{m}^{6} \mathrm{~A}$ and $5^{\prime}$ cap-specific terminal $\mathrm{m}^{6} \mathrm{Am}$ modification in different contexts $(16,17)$. Until now, a dozen of $\mathrm{m}^{6} \mathrm{~A}$ reader proteins have been identified and characterized. Among them, YT521-B homology (YTH)-domain containing protein family, including three YTHDF proteins (YTHDF1/2/3) plus two YTHDC proteins (YTHDC1/2) selectively recognize and directly binds to $\mathrm{m}^{6} \mathrm{~A}$ tag on RNA. YTHDF1 is well-known to directly promote translation of target mRNAs by the recruitment of elF3, a key component of translation initiation complex, to $\mathrm{m}^{6} \mathrm{~A}$ modified transcripts (18). On the other hand, YTHDF2 has been known for its significant role in accelerating mRNA degradation through direct recruitment of the CCR4-NOT deadenylase complex (19) or HRSP12-RNase P/MRP complex (20). Next, it was reported that YTHDF3 not only promotes protein synthesis in synergy with YTHDF1, but also affects methylated mRNA decay mediated through YTHDF2 (21). However, a common theme of YTHDF proteins in recent studies is that all three YTHDF proteins would have similar functions and compensate for each other, which is supported by their highly conserved sequence similarity, similar localization in the cytoplasm, as well as their tendency to bind the same targets $(22,23)$. Thus, the functions of all three YTHDF proteins should be carefully re-examined in order to resolve the controversy whether YTHDF proteins serve distinct or redundant roles in different biological contexts.

Next, YTHDC1 is widely distributed in the nucleus and appears to regulate alternative splicing, by recruiting RNA splicing factor SRSF3, while blocking SRSF10 from binding to mRNAs (24). Moreover, it was also reported that YTHDC1 interacts with SRSF3 and NXF1 to promote the $\mathrm{m}^{6} \mathrm{~A}$-dependent mRNA nuclear export (25), as well as regulates the transcrip- 
tional inactivation of $X$ chromosomal genes mediated by XIST (26). On the other hand, YTHDC2, a putative RNA helicase, has been characterized as a key protein to enhance the translation efficiency (27).

Apart from YTH proteins, a number of other $\mathrm{m}^{6} \mathrm{~A}$ readers have been identified. For instance, HNRNPC/G and HNRNPA2B1, which bind target RNAs through $\mathrm{m}^{6} \mathrm{~A}$-mediated destabilization of secondary structure, have been shown to regulate pri-miRNA processing and translation (28). Additionally, insulin-like growth factor 2 mRNA-binding proteins 1-3 (IGF2BP1/2/3), as well as Fragile $X$ mental retardation protein (FMRP) were also shown to preferentially bind to $\mathrm{m}^{6} \mathrm{~A}$-modified mRNAs through evolutionarily conserved RNA recognition element, such as $\mathrm{K}$ homology $(\mathrm{KH})$, RNA recognition motif (RRM) and arginine/glycinerich (RGG) domains (29). Lastly, proline rich coiled-coil 2A (Prrc2a) has more recently been identified as a novel $\mathrm{m}^{6} \mathrm{~A}$ reader protein, which regulates oligodendroglial specification and myelination (30). Collectively, multiple types of $\mathrm{m}^{6} \mathrm{~A}$ reader proteins are specifically recruited by $\mathrm{m}^{6} \mathrm{~A}$-tagged RNAs to regulate their metabolism. How the similar $\mathrm{m}^{6} \mathrm{~A}$ moieties in RNA are differentially interpreted by reader proteins in specific biological contexts require additional studies to be understood.

\section{(2'-O)-methylation ( $\mathrm{Nm}$ )}

Unlike other modification, $\mathrm{Nm}$ does not require a specific nucleotide rather it occurs on any kind of bases by adding a methyl group to the 2'-hydroxyl of the ribose molecule (31). In general, $\mathrm{Nm}$ can influence RNAs in different ways as it can increase hydrophobicity, protect RNAs from nuclease attacks, stabilize helical structures and affect interaction between modified RNAs and proteins (32). Nm is frequently deposited at internal region of rRNAs and small regulatory RNAs, though tRNAs and mRNAs also have considerable sites for this modification (33). To date, several $\mathrm{Nm}$ methyltransferases have been identified. For example, FTSJ1 is a tRNA 2'-O-methyltransferase that targets the $\mathrm{C}_{32}$ and $\mathrm{N}_{34}$ positions in the anticodon loop of tRNA ${ }^{\text {Phe }}$ and RRNA $^{\text {Trp }}$ (34). TRMT44 is a putative 2'-O-methyluridine methyltransferase predicted to methylate residue 44 in $t R N A^{\text {Seq }}$ (35). In addition, Fibrillarin (FBL) is localized in the dense fibrillar component (DFC) of the nucleolus where newly synthesized pre-ribosomal RNAs reside and methylates specific rRNA targets with help from C/D box family snoRNA (36). Last, CMTR1 is a 2'-O-methyltransferase that modifies the first transcribed nucleotide of the mRNA (37). On the other hand, it remains unclear whether $\mathrm{Nm}$ modification is reversible and recognized by specialized proteins for further downstream pathways due to lack of knowledge of defined eraser or reader proteins.

\section{5-methylcytosine $\left(\mathrm{m}^{5} \mathrm{C}\right)$}

Although methylation of cytosine has been described and characterized as a major epigenetic mark that is frequently added to $\mathrm{CpG}$ region in eukaryotic $\mathrm{DNA}, \mathrm{m}^{5} \mathrm{C}$ can also be detected across various RNA species, especially at tRNA and rRNA (38).
Previous studies have reported that $\mathrm{m}^{5} \mathrm{C}$ is related to nuclear export (39) and translation efficiency (40) for certain target RNAs, but general regulatory functions of $\mathrm{m}^{5} \mathrm{C}$ on gene expression and its precise mechanism still need more further investigation. Additionally, deposition patterns of $\mathrm{m}^{5} \mathrm{C}$ on RNA are enriched at CG dinucleotides adjacent to transcription initiation sites of mRNA (38). Among several eukaryotic $\mathrm{m}^{5} \mathrm{C}$ methyltransferases, two key writer proteins, DNMT2 and NSUN2, are have been separately focused on their functions. Originally identified as eukaryotic cytosine-5-DNA methyltransferase, DNMT2 also serves as a RNA $\mathrm{m}^{5} \mathrm{C}$ methyltransferase, mainly affecting stability and biogenesis of tRNA (41). Conversely, NSUN2 shows broader target specificity, including mRNAs, long non-coding RNAs (IncRNAs) and other small regulatory RNAs, such as vault RNAs, 7SK and Y-RNAs with non-overlapping manner to DNMT2 (38). Very similar to removal pathway of DNA, RNA $\mathrm{m}^{5} \mathrm{C}$ can be oxidized by ten-eleven translocator (TET) family proteins, giving rise to 5-hydroxymethylcytosine, then 5-formylcytosine and 5-carboxycytosine (42). Although it should be addressed whether oxidized form of cytosine in RNA can be changed to uracil that is suitable for appropriate base-excision repair process, the fact that C-to- $\mathrm{U}$ conversion is common phenomenon in RNA and the emergence of key enzyme, SMUG1, which remove 5-methlyuracil in RNA support the possibility that reversible $\mathrm{m}^{5} \mathrm{C}$ metabolism is likely to be similar to that of DNA (43). Unfortunately, less about exact reader protein for $\mathrm{m}^{5} \mathrm{C}$ is known so far, except for ALYREF nuclear exporter (39), leaving a question to be addressed.

\section{Pseudouridine $(\psi)$}

$\psi$ is known as one of the most prevalent RNA modifications dominantly found in non-coding RNA, though it is also detectable in a subset of mRNAs at a low level (44). Intrinsically, isomerization of uridine to $\psi$, in which additional hydrogen bonds are adopted, enhances the stability of RNAs by increasing base stacking interactions, resulting in stable secondary structure formation (45). Moreover, $\psi$ is thought to be a key molecular regulator that affects translation efficiency, processing of rRNA and snRNA, as well as telomerase activities (44). Installation of $\psi$ is modulated by two different pathways: guide RNA-dependent, in which the guide H/ACA box snoRNA is required for base pairing to target RNA to be modified, and guide RNA-independent pathway, in which stand-alone protein searches target RNAs and catalyzes the formation of $\psi$. For instance, human Dyskerin (DKC1) belongs to guide RNA-dependent writers of $\psi$ that is also involved in sno-ribonucleoprotein complex (46), whereas pseudouridine synthases (PUS) family proteins, including PUS1, PUS3, PUS7 and PUS10, are included in guide RNA-independent writers (45) and some of these PUS proteins directly recognize target RNAs in structure-dependent manner (47). Unfortunately, there are no direct eraser and reader proteins identified so far, leaving the reversibility of pseudouridylation and the downstream mechanisms unclear. Taken together, further studies to screen regulatory pro- 
teins will be required for better understanding of this epitranscriptomic mark.

\section{ROLES OF EPITRANSCRIPTOMIC REGULATION IN NEURODEVELOPMENT}

The neurodevelopment of animals is composed of a lot of biological events, including early fate decision of neural stem/progenitor cells, generation of neurons and glial cells, migration of post-mitotic immature neurons, formation of synapses, programmed cell death, synaptic rearrangement, as well as maintenance and reconstruction of neurons throughout the postnatal stages. In this section, we will overview the dynamic changes of epitranscriptomic modifications and their functional contribution of transcriptome plasticity in different steps of neurodevelopment (Fig. 2).

\section{Embryonic neurogenesis}

$\mathbf{m}^{6} \mathrm{~A}$ : During embryonic cortical development, $\mathrm{m}^{6} \mathrm{~A}$ modification regulates proliferation and differentiation of multipotent neural stem cells (2). For example, a study with nervous system-specific conditional knockout (cKO) mice of Mett/14 revealed that $\mathrm{m}^{6} \mathrm{~A}$ temporally controls transcriptional transition from maintenance of neural stem cell/progenitor cells (NSPCs) to pro-neurogenic, and its dysregulation led to loss of differentiation capability, prolonged cell cycle and extended cortical neurogenesis into postnatal stages (48). The $\mathrm{m}^{6} \mathrm{~A}$-modified mRNAs in the developing cortex were highly enriched for gene ontologies corresponding to cell cycle, stem cells and neuronal differentiation, exhibiting markedly reduced half-life compared to $m R N A s$ without $\mathrm{m}^{6} \mathrm{~A}$ modification. These results suggest that $\mathrm{m}^{6} \mathrm{~A}$ is responsible for destabilization of target mRNAs that are involved in either self-renewal or differentiation of NPCs in the cortex, which is required for the rapid transition of gene expression profiles for proper temporal progres-

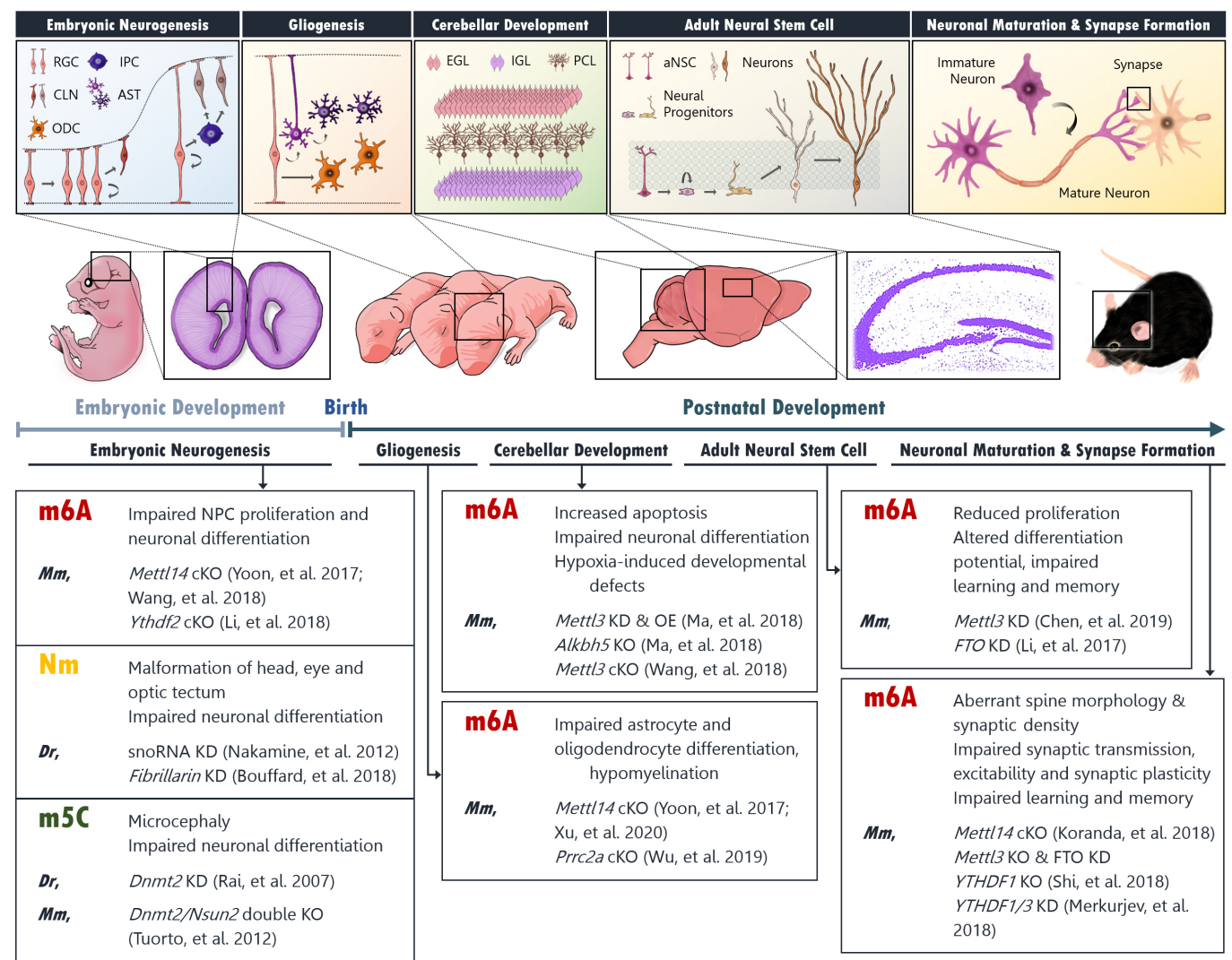

Fig. 2. The roles of epitranscriptome in neurodevelopment. During the embryonic and postnatal development, RNA modifications play important roles in regulation of transcriptome plasticity, by which different developmental programs of the CNS, such as embryonic neurogenesis, gliogenesis, cerebellar development, adult neurogenesis, neuronal maturation, and synapse formation are precisely progressed. Bottom panels comprehensively summarize the physiological functions of $\mathrm{m}^{6} \mathrm{~A}, \mathrm{Nm}$, and $\mathrm{m}^{5} \mathrm{C}$ in neurodevelopment revealed by of loss- and/ or gain-of-function studies about related epitranscriptomic machinery. RGC, radial glial cell; IPC, intermediate progenitor cell; CLN, cortical layer neuron; AST, astrocyte; ODC, oligodendrocyte; EGL, external granular layer; IGL, inner granule cell layer; PCL, Purkinje cell layer; aNSC, adult neural stem cell; Mm, Mus musculus; Dr, Danio rerio. 
sion of cortical neurogenesis (48). Interestingly, loss of $\mathrm{m}^{6} \mathrm{~A}$ tagging in Mett/14 cKO cortex led to aberrant misexpression of neuronal lineage genes, such as Tbr2 and Neurod1, in NPCs, suggesting that NPCs are transcriptionally "pre-patterned" for differentiation by actively transcribing neuronal lineage genes, which are rapidly degraded through $\mathrm{m}^{6} \mathrm{~A}$-mediated $\mathrm{mRNA}$ degradation (2).

In addition, $\mathrm{m}^{6} \mathrm{~A}$ was shown to also regulate histone modifications at genome-wide level (49). In detail, NPCs derived from Mett/14 cKO mice exhibited globally increased histone H3 acetylation at lysine $27(\mathrm{H} 3 \mathrm{~K} 27 \mathrm{ac})$, histone $\mathrm{H} 3$ trimethylation at lysine $4(\mathrm{H} 3 \mathrm{~K} 4 \mathrm{me} 3)$ and histone $\mathrm{H} 3$ trimethylation at lysine 27 (H3K27me3). In this study, the stability of several transcripts encoding histone remodeling proteins, such as CBP and p300, were regulated in $\mathrm{m}^{6} \mathrm{~A}$-dependent manner, leading to global alterations of histone modifications by dysregulated chromatin remodeling proteins (49). Moreover, a recent study reported that $\mathrm{m}^{6} \mathrm{~A}$-tagged nascent transcript on chromatin recruited H3K9me2 demethylase KDM3B via YTHDC1, resulting in the removal of repressive histone mark $\mathrm{H} 3 \mathrm{~K} 9 \mathrm{me} 2$ and enhancement of downstream gene expression (50). Given that the dynamic epigenome controlling mechanisms are critical for appropriate gene expression in embryonic development (51), these studies indicate that the linkage between the epigenetic and epitranscriptomic marks is also important for proper progression of the embryonic neurogenesis.

In addition, $\mathrm{m}^{6} \mathrm{~A}$ reader proteins also play a significant role in brain development. For example, YTHDF2 mediated the decay of certain transcripts involved in JAK-STAT signaling pathway, which significantly contributes to normal neuroprotection and neurite outgrowth. Consistently, Ythdf2-depleted mice exhibited impaired proliferation and differentiation of NPCs similar with Mett/14 CKO mice, again highlighting the essential function of $\mathrm{m}^{6} \mathrm{~A}$ in NPC maintenance and neuronal differentiation during cortical development (52).

$\mathrm{Nm}$ : Several studies suggested that $\mathrm{Nm}$ modification on tRNA and rRNA are likely to be related to neurodevelopment. For example, an tRNA 2'-O-methyltransferase, FTSJ1, was shown to be highly expressed in human fetal brain compared to other tissues, and FTS/1 mutations have been identified as a risk factor of non-syndromic X-linked intellectual disability (ID) (53). Not only to tRNA, but Nm modification is also added to rRNAs, which requires the site-specific guides of small nucleolar RNAs (snoRNAs). Until now, two different families of snoRNAs have been well classified by their structural and functional features. Among them, C/D box snoRNAs are known to mediate 2'-O-methylation of rRNAs, while H/ACA box snoRNAs are responsible for pseudouridylation (33). Intriguingly, it was shown that loss of three different snoRNAs in zebrafish caused the failure of normal rRNA methylation, eventually leading to severe malformation of head region (54) and, consistently, zebrafish that lacks FBL, an essential nucleolar $\mathrm{Nm}$ writer protein responsible for proper pre-rRNA processing, exhibited abnormal optic tectum and the eye development due to impaired neural differentiation (55). Furthermore, C/D box snoRNAs also have been shown to be associated with Prader-Wili syndrome (PWS), a complex genetic condition that affects many parts of the body, especially the central nervous system (56). Interestingly, previous studies have demonstrated that PWS is likely to be caused by the loss of a group of imprinted snoRNAs $(56,57)$, which suggests that Nm modification may govern the neuronal differentiation and tissue development.

$\mathbf{m}^{5} \mathbf{C}$ : The roles of $\mathrm{m}^{5} \mathrm{C}$ on embryonic neurogenesis are different across species. For instance, morpholino-based knockdown of Dnmt2 in zebrafish embryo exhibited reduced early proneural marker Neurog1 (ngn-1) in hypothalamus and diencephalon, together with severe defects in neurogenesis (58). However, Dnmt2-deficient mice did not show severe developmental phenotypes because of the compensation by another major $\mathrm{m}^{5} \mathrm{C}$ methyltransferase in mice, Nsun2 (59). Interestingly, it was shown that Nsun2-depletion solely caused microcephaly phenotypes both in human and mice (60), unlike the case of Dnmt2. This observation was further supported by a study demonstrating that Nsun2-mediated $\mathrm{m}^{5} \mathrm{C}$ modification regulates neural stem cell differentiation and motility in mouse (61). Consistently, Dnmt2 and Nsus2 double knockout, which lacks $90 \%$ of total $\mathrm{m}^{5} \mathrm{C}$, exhibited significantly undeveloped cortex (62), suggesting that $\mathrm{m}^{5} \mathrm{C}$ modification is required for normal mouse brain development and cellular differentiation.

$\psi$ : Although exact functions of $\psi$ in neurodevelopment have yet to be investigated, several recent studies have suggested that pseudouridine could play putative biological roles in proper formation of the central nervous system. Among the TruA family proteins, for instance, PUS3 transcripts are exclusively enriched in the nervous system of developing mouse embryo (63). In addition, a homozygous truncating mutation in PUS3 in human patients with a history of global developmental delay and severe ID showed decreased levels of pseudouridine in tRNA (64). Similar to PUS3, H/ACA box-mediated pseudouridine synthase, DKC1 also showed enhanced expression level of transcripts restricted to the mitral cell layer of the olfactory bulb and neuronal tissues in telencephalon region (65), suggesting that pseudouridylation is likely to have important roles in neurodevelopment.

\section{Gliogenesis}

Gliogenesis proceeds not only in a prenatal but also in a postnatal development. Mett/14 cKO displayed severe defects in neurogenic/gliogenic transition and astrocyte differentiation (48). For oligodendrocyte differentiation and myelination, $\mathrm{m}^{6} \mathrm{~A}$ mRNA methylation regulates splicing pattern of paranode component NF155, and its dysregulation led to attenuation of the differentiation of oligodendrocytes and myelinations (66). In addition, Prrc2a, newly identified $\mathrm{m}^{6} \mathrm{~A}$ reader, stabilized Olig2 mRNA in oligodendrocyte, and promoted subsequent specification and myelination of oligodendrocytes (30). 


\section{Cerebellar development}

Cerebellum proceeds its development until postnatal period in chronological order (67). Mettl3-depleted cerebellum showed the enhancement of mRNA stability related to apoptosis, leading to premature cerebellar granule cell death in external granular layer and subsequent cerebellar hypoplasia. In addition, the neuronal layer and structures of Purkinje cell and Bergmann glia cells malformed, which can be resulted from dysregulation of splicing of synapse-associated genes like Grin1 (68). The other study uncovered that balanced expression of $\mathrm{m}^{6} \mathrm{~A}$ writers and readers fine-tunes mRNA methylation in a time-specific way, which leads to normal cerebellar development (69). In addition, under hypoxia condition, Alkbh5-deletion caused abnormal cell proliferation and differentiation in the cerebellum by impaired nuclear export of the hypermethylated RNAs, suggesting that the dynamic regulation of $\mathrm{m}^{6} \mathrm{~A}$ epitranscriptome by Alkbh5-mediated demethylation has important physiological roles depending environmental conditions in vivo (69).

\begin{abstract}
Adult neural stem cell
After birth, adult neural stem cells (aNSCs) reside in the subgranular zone (SGZ) of the dentate gyrus in the hippocampus and subventricular zone (SVZ) of the lateral ventricles in mouse (70). aNSCs are also regulated in a genetic and epigenetic mechanism upon environmental stimuli and neuronal activity (70), as well as epitranscriptomic regulation. For example, Mettl3 depletion in aNSCs led to reduced proliferation of aNSCs and alteration of differentiation potential toward glial lineage (71). Depletion of an eraser protein, Fto, in aNSC also resulted in reduced proliferation and differentiation of aNSCs in the SGZ, leading to impairment of learning and memory (72). Interestingly, $\mathrm{m}^{6} \mathrm{~A}$ was present on the transcripts of histone methyltransferase Ezh2, and its protein level and consequent H3K29me3 level were markedly dysregulated upon Mettl3 knockdown (71), suggesting highly interconnected regulation between epigenome and epitranscriptome in neurodevelopment. As we mentioned already, interactions between epigenetic and epitranscriptomic regulations were also identified in other systems during neurodevelopment $(8,49)$.
\end{abstract}

\section{Neuronal maturation and synapse formation}

Complex tasks in the CNS including learning, memory, and cognition require the precise and accurate formation of neural networks through synapse formation and function (73). $\mathrm{m}^{6} \mathrm{~A}$ modification has been suggested to play a role in neuronal maturation and synapse formation (74) as well as in synaptic plasticity (75). Mettl14 depletion led to downregulation of $\mathrm{m}^{6} \mathrm{~A}$ level on mRNAs encoding synapse-specific proteins (76). In cerebellum, Mettl3-mediated $\mathrm{m}^{6} \mathrm{~A}$ regulation affects alternative splicing of synapse-associated pre-mRNAs (68). Ythdf1 regulates activity-dependent neural responses related to learning and memory, and depletion of Ythdf1 showed impairment of synaptic transmission and long-term potentiation in the mouse hippocampus (77). In addition, depletion of Ythdf1 or Ythdf3 in cultured hippocampal neurons led to dysregulation of excitatory synaptic transmission as well as immature spine morphology (78). In another study, Mettl3-depletion in adult mouse brain caused impaired long-term memory formation without morphological alteration of the brain (79). These findings imply that $\mathrm{m}^{6} \mathrm{~A}$-mediated regulations have crucial roles at synapse for both development and activity-dependent modulation of neural networks.

Taken together, several types of RNA modifications appear to play important roles in controlling RNA metabolisms, such as splicing, degradation, translation, as well as crosstalk with epigenetic mechanisms to regulate gene expression, all of which are essential for proper development of the CNS.

\section{DYSREGULATION OF EPITRANSCRIPTOME IN HUMAN NEURONAL DISORDERS}

\section{Neurodegenerative disorders}

Neurodegenerative disorders, such as Alzheimer's Disease (AD) and Parkinson's Disease (PD), are highly correlated with aging (80). While several factors including genomic instability, malfunction of mitochondria, and cellular senescence are hallmarks of aging that affect neurodegeneration (80), it was also reported that mRNA modifications such as $\mathrm{m}^{6} \mathrm{~A}$ and $\mathrm{m}^{5} \mathrm{C}$ regulate stability of mRNAs which encode senescence-associated proteins such as AGO2 $(81,82)$. In addition, another study showed that defect in ALKBH8, tRNA methyltransferase was related to senescence with downregulation of selenoprotein synthesis and elevation of reactive oxygen species in mouse embryonic fibroblasts (83). Regarding these points, the perturbation of epitranscriptomic regulation might be a possible mechanism of neurogenerative disorders (Fig. 3).

Lesion in the sciatic nerve induces the elevation of $\mathrm{m}^{6} \mathrm{~A}$ levels on regeneration-associated genes and protein translation machinery components in adult mouse dorsal root ganglion (DRG) to enhance injury-induced protein translation essential for axon regeneration. Indeed, loss of Mett/14 or Ythdf1 attenuated protein translation related to axon regeneration in adult DRGs and subsequent axon regeneration (84). Furthermore, Pten deletion-induced axon regeneration of retinal ganglion neurons in the adult CNS was attenuated upon Mettl14 knockdown, suggesting $\mathrm{m}^{6} \mathrm{~A}$-dependent post-transcriptional regulation is important for neuronal regeneration in both the CNS and the peripheral nervous system. Because the failure of neuronal regeneration is tightly connected to neurodegenerative disorders, it is interesting to examine how $\mathrm{m}^{6} \mathrm{~A}$-dependent regeneration pathways contributes to the protection of neurodegenerative disorders in aging.

Stroke is an acute focal injury in the CNS, but if not cured immediately, causes poststroke neurodegeneration and further AD (85). Using transient middle cerebral artery occlusion (MCAO), a popular model of stroke in mouse, a study found that global level of $\mathrm{m}^{6} \mathrm{~A}$ on transcripts related to inflammation, apoptosis, and transcriptional regulation increased after 12 to 


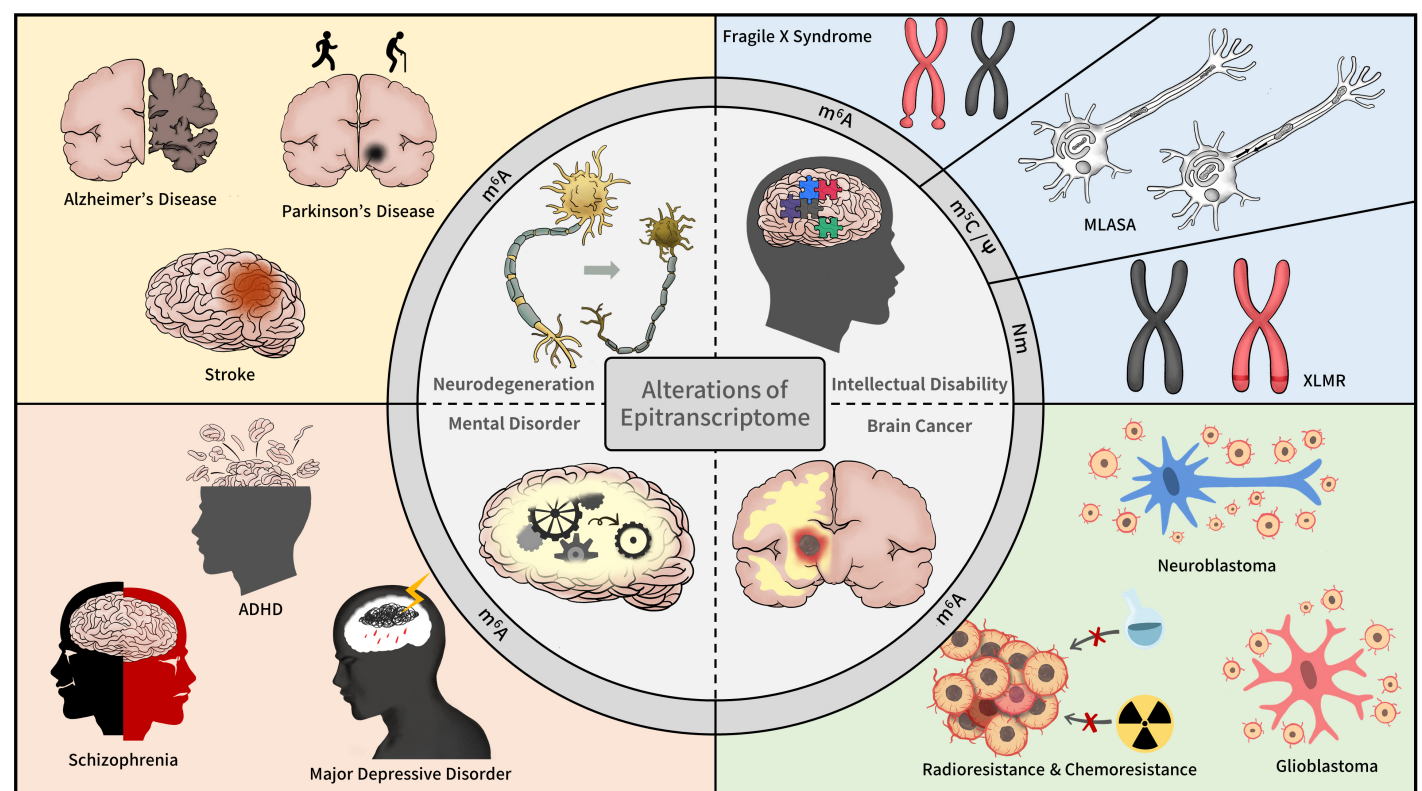

Fig. 3. Epitranscriptomic regulation in major brain disorders. Epitranscriptomic RNA modifications are involved in multiple types of brain disorders. Human genetic analysis and animal model studies revealed that various RNA modifications and their regulatory machineries have critical roles in etiology of neurogenerative disorders, intellectual disability, mental disorders, and brain cancers. ADHD, attention deficit hyperactivity disorder; MLASA, mitochondrial myopathy, lactic acidosis, and sideroblastic anemia; XLMR, X-linked mental retardation; $\mathrm{m}^{6} \mathrm{~A}$, N6-methyladenosine; $\psi$, pseudouridine; $\mathrm{m}^{5} \mathrm{C}$, 5-methylcytosine; $\mathrm{Nm}, 2^{\prime}$-O-methylation.

24 hours of MCAO (86). The $\mathrm{m}^{6} \mathrm{~A}$ writers were unaltered, but the $\mathrm{m}^{6} \mathrm{~A}$ eraser Fto decreased significantly after stroke, but the functional contribution of $\mathrm{m}^{6} \mathrm{~A}$ in stroke and injury response is yet unclear.

Alzheimer's disease (AD) is a one of the most common neurodegenerative disease in the old, and progresses into dementia and cognitive impairment (87). In human genetic studies, different genetic variants of FTO have been reported to be associated with $A D$ risk $(88,89)$. It was shown that Fto activated the phosphorylation of Tau in a mTOR-dependent manner, and conditional knockout of Fto in the neurons reduced the cognitive deficits in AD model mice (90). APP/PS1 double transgenic mouse, which is well-known for AD model, displayed elevated $\mathrm{m}^{6} \mathrm{~A}$ and Mettl3 level as well as reduced Fto level in the cortex and the hippocampus (91). Moreover, a recent study showed that FMRP, a $\mathrm{m}^{6} \mathrm{~A}$ reader protein, bound to Adam9 and Psen1 which are APP secretases to regulate their nuclear export. When FMRP was absent, cytoplasmic level of Adam9 and Psen1 were downregulated, leading to aberrant APP processing (92). Additionally, a study showed that Cmtr1, a Nm writer, was increasingly upregulated by the age of $A D$ model mouse (5xFAD line), suggesting other epitranscriptomic modifications beyond $\mathrm{m}^{6} \mathrm{~A}$ would be also involved in neurodegenerative diseases (93).

Parkinson's Disease (PD) is one of the most commonly diagnosed neurodegenerative movement disorder with the symptoms such as tremor and rigidity (94). Several genetic factors and mechanisms are known to be associated with PD, such as loss of dopaminergic neurons and accumulation of misfolded alpha-synuclein (94). FTO overexpression or $\mathrm{m}^{6} \mathrm{~A}$ reduction in dopaminergic neurons upregulated GRIN1 expression, leading to subsequent elevation of oxidative stress and $\mathrm{Ca}^{2+}$ influx and apoptosis (95). On the other hand, Fto depletion in dopaminergic neurons caused impaired dopamine receptor type 2 mediated signaling, which led to attenuated activity of $G$ protein-coupled inwardly-rectifying potassium channel (GIRK channel) and dysregulation of behaviors controlled by dopaminergic transmission (96). Recently, entacapone, known as catechol-o-methyltransferase inhibitor used for PD treatment, has been suggested as FTO inhibitor (97). Entacapone directly bound to and deactivated FTO, then inhibited the activity of transcription factor forkhead box protein $\mathrm{O} 1$ (FOXO1). As genetic and epigenetic factors have been suggested to play a role in regulating neurodegenerative diseases, specific molecular and cellular mechanisms in epitranscriptomic way are yet to be more investigated.

\section{Intellectual disability}

Intellectual disability (ID) is a complicated developmental disorder concluding cognitive impairment, learning failure, maladjustment to social environment, and so on. Several genetic factors including Frm1 mutation in Fragile X syndrome 
were found to be cause of ID, and autosomal dominant and recessive genes related to ID have been increasingly accumulated (98). In addition to genetic factors, epigenetic alterations in histone modification and chromatin structure affect ID occurrence (99). Mutations in a number of X-linked genes such as ATRX and MeCP2 dysregulated chromatin structure and subsequent gene expression pattern (99).

Among X-linked genes, Fragile X Mental Retardation Protein (FMRP) is related to synaptic function, and depletion of this protein caused degradation of its target mRNAs (100). Interestingly, FMRP interacts with YTHDF2, $\mathrm{m}^{6} \mathrm{~A}$ reader protein to enhance stability of its target mRNAs. Moreover, frameshift mutation on METTL5, which is 18s ribosomal RNA methyltransferase (101) abundantly expressed in the hippocampus, caused ID with symptoms in moderate to severe level accompanied with microcephaly (102).

Homozygous mutation of truncation form in PUS3 is linked to ID with decreased levels of pseudouridine in tRNA (64). In the case of homozygous mutation on PUS7 in human caused ID as well as microcephaly (103). These patients with PUS7 mutation showed decreased level of pseudouridylation in mRNA as well as tRNA. In addition, mutations in Dyskerin, rRNA pseudouridine synthase, are linked to X-linked recessive dyskeratosis congenita and Hoyeraal-Hreidarsson syndrome, which both show symptoms of microcephaly and some extent of mental deficiency related to ID (65). Moreover, missense mutation in PUS1 was found to be the cause of Myopathy-lactic acidosis-sideroblastic anemia (MLASA) with altered expression in muscle and brain (104). In other research, two different genetic mutations on PUS1 were found to cause MLASA and consequent ID (105).

NSUN2, $\mathrm{m}^{5} \mathrm{C}$ writer, was also suggested as the cause of ID. For example, mutations in NSUN2 are the risk factor of MLASA syndrome, leading to delayed response of sensory signals and mild cognitive impairment (106). Through whole-exome sequencing, it was shown that mis-spliced mutants in NSUN2 caused Dubowitz Syndrome that displays microcephaly and ID (107). In another study, mutation in NSUN2 was suggested to be a risk of ID by genetic analysis of human pedigree. Also, mutation in NSUN2 caused the mislocalization of NSUN2 protein in the nucleus of Purkinje cells in the cerebellum (108).

From 1990s, FTJS1, Nm writer, has been reported for its mutation to be associated with nonsyndromic X-Linked mental retardation (NS-XLMR) in human genetic studies $(109,110)$. Moreover, single nucleotide polymorphisms (SNPs) $(111,112)$ or copy number variations (113) of FTS/1 were associated with the risks of intellectual ability and NS-XLMR. Firstly, it was reported that FTSJ1 has a function of methyltransferase which targets $\mathrm{Cm}$ and $\mathrm{Gm}$ of $\mathrm{tRNA} \mathrm{A}^{\mathrm{Phe}}$, and its malfunction methylating Gm can be associated to NS-XLMR (53). While investigating molecular mechanism, one study found that FTSJ1 interacts with WDR6 in cytoplasm, so FTSJ1 can methylate Gm34 tRNA ${ }^{\text {phe }}$ with the prerequisite of $m^{1} \mathrm{G} 37$ (114). Recently, based on gene trapped stem cell line, Ftsj1 deficient mouse line showed ID symptoms as well as alteration in metabolism and immune function (115). Also, TRMT44, a putative Nm writer, was suggested to be associated with partial epilepsy with pericentral spikes (PEPS) through methylating on tRNA ${ }^{\text {Ser }}$ (35). The exact role and precise mechanism of each writers and other epitranscriptomic factors in ID pathogenesis should be investigated further.

\section{Mental disorders}

FTO, which demethylates both $\mathrm{m}^{6} \mathrm{~A}$ and $\mathrm{m}^{6} \mathrm{Am}\left(\mathrm{m}^{6} \mathrm{~A} / \mathrm{m}\right.$, collectively), has been actively investigated in mental disorders even before generally known as being related to RNA modification. Exposure to arsenite led to decrease of Fto expression, which increased $\mathrm{m}^{6} \mathrm{~A}$ level and subsequent dysregulation related to deficits in dopaminergic neurotransmission (116). Several SNPs of FTO were associated with a risk for ADHD with symptoms of memory and cognitive defects (117). Even though specific mechanism is unclear, $\mathrm{ZC} 3 \mathrm{H} 13$ polymorphism has been reported to be associated with schizophrenia risk (118). These results imply that $\mathrm{m}^{6} \mathrm{~A}$ regulation affects dopaminergic midbrain circuits related to mental disorders such as schizophrenia.

Glucocorticoid response upon chronic psychological stress, which underlies several mental disorders, induces profound time-specific alteration of $\mathrm{m}^{6} \mathrm{~A} / \mathrm{m}$ landscape $(75,119)$. Deletion of Mettl3 and Fto in adult neurons altered $\mathrm{m}^{6} \mathrm{~A} / \mathrm{m}$ epitranscriptome, increased fear memory, and changed transcriptome response to fear and synaptic plasticity (75), suggesting that dysregulation of the $\mathrm{m}^{6} \mathrm{~A} / \mathrm{m}$ response may contribute to the pathophysiology of stress-related mental disorders. Regarding $\mathrm{m}^{6} \mathrm{~A} / \mathrm{m}$ level is dysregulated in major depressive disorder patients $(75,120)$, and certain $\mathrm{m}^{6} \mathrm{~A}$ regulator like ALKBH5 is highly associated with the risk of major depressive disorder (121), the detail roles of $\mathrm{m}^{6} \mathrm{~A} / \mathrm{m}$ in the etiology of major depressive disorder need to be addressed further. Moreover, Mettl14 deletion in dopaminergic neurons led to dysregulation of neuronal excitability and impairment of striatal-mediated learning (76), indicating that epitranscriptomic regulators can be involved in mental diseases related to dysfunction of the dopaminergic system.

\section{Brain cancer}

Neuroblastoma is known to be the most common solid tumor found in early children and derived from several genetic aberrations. Interestingly, polymorphisms in METTL3 and METTL14 are highly associated with neuroblastoma susceptibility (122, 123). In a study using human neuroblastoma cells, $\mathrm{m}^{6} \mathrm{~A}$ modification on 3'-UTR of MYCN interacted with miR-98, which inhibited cell proliferation, migration, and invasion of neuroblastoma cells (124). In another study, several $\mathrm{m}^{6} \mathrm{~A}$ writer proteins (METTL14, WTAP) and reader proteins (YTHDF1, HNRNPC, and IGF2BP2) were suggested to be hallmarks of tumor malignancy using a hundred of human neuroblastoma tissues (125). 
Glioma, which is one of the most common malignant tumor of astrocytes in brain, has four different grades defined by $\mathrm{WHO}$ (I-IV): low-grade and anaplastic astrocytoma (WHO grades I-III) and glioblastoma (WHO grade IV) (126). The prognosis of glioma patients is quite poor even its treatment has been evolved (127). Among the $\mathrm{m}^{6}$ A-related proteins, Wilms' tumor 1-associating protein (WTAP) is implicated for the marker of glioblastoma (128). WTAP was over-expressed in glioblastoma with 169 clinical samples with glioma patients, and the higher expression of WTAP was correlated with poorer prognosis (128), suggesting $\mathrm{m}^{6} \mathrm{~A}$ regulatory proteins may have important roles in tumor progression.

Glioblastoma stem cells (GSCs) were suggested as a primary source that contributes to tumor propagation, maintenance, and treatment resistance (129), which $\mathrm{m}^{6} \mathrm{~A}$-mediated regulation also takes part in. For example, GSC-mediated tumorigenesis was markedly promoted by knockdown of METTL3 or METTL14, by inducing changes in $\mathrm{m}^{6} \mathrm{~A}$ profiles and subsequently altering mRNA expression of genes with critical biological functions in GSCs, such as ADAM19 (130). Meanwhile, ALKBH5 is highly expressed in GSCs and demethylases $3^{\prime}$ UTR of FOXM1 nascent RNAs to enhance FOXM1 expression and tumorigenesis of GSCs (131). On the other hand, it was also reported that elevated expression of METTL3 in GSCs enhanced the maintenance of GSCs through SOX2 stabilization compared to elevation of that in differentiated glioma cells. Moreover, SOX2dependent DNA repair was more activated in METTL3 expression-elevated GSCs, which led to radioresistance (132). These results suggest $\mathrm{m}^{6} \mathrm{~A}$-mediated regulations govern various steps for genesis and progression of glioma.

As altered histone modification and their modifiers are related to glioma genesis, these epigenetic regulators have been regarded as therapeutic targets and applicable biomarkers (133). Similarly, epitranscriptomic factors have been suggested as applicable biomarkers and therapeutic targets in gastrointestinal cancer (134) and renal cancer (135). To identify biomarkers of glioblastoma, $\mathrm{m}^{6} \mathrm{~A}$-IncRNA co-expression networks were constructed through statistical analysis of primary glioblastoma patients, which screened four IncRNAs with their co-expressed functional genes. In that the IncRNA expression was correlated with the effect of $\mathrm{m}^{6} \mathrm{~A}$ modification, it is suggested that posttranscriptional regulation of noncoding RNAs may have a significant role in dynamic gene expression control of glioblastoma (136). In addition, twenty-four IncRNAs were explored to be prognostic $\mathrm{m}^{6} \mathrm{~A}$-related IncRNAs, which shows the distinct $\mathrm{m}^{6} \mathrm{~A}$ status between low- and high-risk subgroups of lowergrade glioma patients (137). Moreover, it was reported that FTO inhibition enhanced effectiveness of chemotherapy of glioma (138), and a newly synthesized inhibitor of ALKBH5 successfully kept specific glioblastoma cell line from migration and invasiveness (139), suggesting that epitranscriptomic regulators will be considered as important targets for development of potential therapeutic intervention of brain cancers in the future.

\section{CONCLUSION AND FUTURE DIRECTIONS}

In summary, we have reviewed overall mechanisms of epitranscriptomic gene regulation and endeavors to identify the physiological functions of various epitranscriptomic modifications and their mechanisms. Indeed, the dynamic regulations of transcriptome plasticity via RNA modifications have been demonstrated to be involved in prenatal and postnatal neurodevelopment ranging from neural stem cell establishment to adult neurogenesis. However, only few of writer, eraser, and reader proteins modulating these neurodevelopmental processes have been investigated in detail. Further studies on regulator proteins of epitranscriptome and cell-type specific reader proteins will be necessary to appreciate the whole picture of dynamic transcriptome plasticity in development and physiology of the brain. In addition, it is still challenging to detect a specific RNA modification with high resolution and low background signals by current epitranscriptome mapping technologies that majorly rely on the sensitivity and the specificity of modification-specific antibodies. Therefore, recently developed antibody-independent approaches $(140,141)$ will greatly improve our understanding on the landscape of epitranscriptome upon various cellular and environmental context at single base-pair resolution.

In addition, we examined several brain disorders including neurodegenerative diseases, intellectual disability, mental disorder, and brain cancer in the context of epitranscriptomic regulation. Accumulating evidences suggest that the dysregulated epitranscriptome is a potent pathological mechanism of brain disorders, together with genetic and epigenetic factors. From this perspective, novel biomarkers to predict disease progression as well as new therapeutics are currently being developed by investigating and modulating epitranscriptomic regulation. Through continued efforts to advance epitranscriptome mapping technologies, to uncover functional mechanisms of key regulatory proteins of RNA modification, and to develop novel reagents to control disease-related features of transcriptome plasticity, we believe our expanding understanding of epitranscriptome will significantly contribute to deciphering the daunting complexity of brain disorders.

\section{ACKNOWLEDGEMENTS}

We thank for wonderful illustrations by Jaewook Lee, and for careful reading and suggestions by Huiseon Hwang. This work was supported by the National Research Foundation of Korea (NRF) grants (2018R1A5A1024261, 2019R1C1C1006600, 2017 M3C7A1047654 to K.-J.Y., the Brain Pool program to N.-S.K.) funded by the Korean Ministry of Science, ICT, and Future Planning (MSIP), and the Young Investigator Grant from the Suh Kyungbae Foundation (to K.-J.Y.), 


\section{CONFLICTS OF INTEREST}

The authors have no conflicting interests.

\section{REFERENCES}

1. Telley L, Govindan S, Prados J et al (2016) Sequential transcriptional waves direct the differentiation of newborn neurons in the mouse neocortex. Science 351, 1443-1446

2. Yoon KJ, Vissers C, Ming GL and Song H (2018) Epigenetics and epitranscriptomics in temporal patterning of cortical neural progenitor competence. J Cell Biol 217, 1901-1914

3. Livneh I, Moshitch-Moshkovitz S, Amariglio N, Rechavi G and Dominissini D (2020) The m6A epitranscriptome: transcriptome plasticity in brain development and function. Nat Rev Neurosci 21, 36-51

4. Zhao BS, Roundtree IA and He C (2017) Post-transcriptional gene regulation by mRNA modifications. Nat Rev Mol Cell Biol 18, 31-42

5. Meyer KD and Jaffrey SR (2017) Rethinking m(6)A readers, writers, and erasers. Annu Rev Cell Dev Biol 33, 319-342

6. Hussain S (2017) Shaping and reshaping transcriptome plasticity during evolution. Trends Biochem Sci 42, 682684

7. Meyer KD, Saletore $Y$, Zumbo P, Elemento O, Mason CE and Jaffrey SR (2012) Comprehensive analysis of mRNA methylation reveals enrichment in 3' UTRs and near stop codons. Cell 149, 1635-1646

8. Liu J, Li K, Cai J et al (2020) Landscape and regulation of $\mathrm{m}(6) \mathrm{A}$ and $\mathrm{m}(6) \mathrm{Am}$ Methylome across human and mouse tissues. Mol Cell 77, 426-440 e426

9. Liu J, An Z, Luo J, Li J, Li F and Zhang Z (2020) Episo: quantitative estimation of RNA 5-methylcytosine at isoform level by high-throughput sequencing of RNA treated with bisulfite. Bioinformatics 36, 2033-2039

10. Li X, Zhu P, Ma S et al (2015) Chemical pulldown reveals dynamic pseudouridylation of the mammalian transcriptome. Nat Chem Biol 11, 592-597

11. Dominissini D, Moshitch-Moshkovitz S, Schwartz S et al (2012) Topology of the human and mouse m6A RNA methylomes revealed by m6A-seq. Nature 485, 201-206

12. Meyer KD, Patil DP, Zhou J et al (2015) 5' UTR m(6)A Promotes Cap-Independent Translation. Cell 163, 999-1010

13. Liu J, Yue Y, Han D et al (2014) A METTL3-METTL14 complex mediates mammalian nuclear RNA N6-adenosine methylation. Nat Chem Biol 10, 93-95

14. Jia G, Fu Y, Zhao X et al (2011) N6-methyladenosine in nuclear RNA is a major substrate of the obesity-associated FTO. Nat Chem Biol 7, 885-887

15. Zheng G, Dahl JA, Niu $Y$ et al (2013) ALKBH5 is a mammalian RNA demethylase that impacts RNA metabolism and mouse fertility. Mol Cell 49, 18-29

16. Wei J, Liu F, Lu Z et al (2018) Differential m(6)A, $\mathrm{m}(6) \mathrm{Am}$, and $\mathrm{m}(1) \mathrm{A}$ demethylation mediated by FTO in the cell nucleus and cytoplasm. Mol Cell 71, 973-985 e975

17. Mauer J and Jaffrey SR (2018) FTO, m(6) Am , and the hypothesis of reversible epitranscriptomic mRNA modifi- cations. FEBS Lett 592, 2012-2022

18. Wang X, Zhao BS, Roundtree IA et al (2015) N(6)-methyladenosine modulates messenger RNA translation efficiency. Cell 161, 1388-1399

19. Du H, Zhao Y, He J et al (2016) YTHDF2 destabilizes $\mathrm{m}(6) \mathrm{A}$-containing RNA through direct recruitment of the CCR4-NOT deadenylase complex. Nat Commun 7, 12626

20. Park $\mathrm{OH}$, Ha H, Lee $\mathrm{Y}$ et al (2019) Endoribonucleolytic cleavage of m(6)A-containing RNAs by RNase P/MRP complex. Mol Cell 74, 494-507 e498

21. Shi H, Wang X, Lu Z et al (2017) YTHDF3 facilitates translation and decay of $\mathrm{N}(6)$-methyladenosine-modified RNA. Cell Res 27, 315-328

22. Zaccara S and Jaffrey SR (2020) A unified model for the function of YTHDF proteins in regulating $\mathrm{m}(6) \mathrm{A}$-modified mRNA. Cell 181, 1582-1595 e1518

23. Lasman L, Krupalnik V, Viukov S et al (2020) Contextdependent functional compensation between Ythdf m6A reader proteins. Genes Dev 34, 19-20

24. Xiao W, Adhikari S, Dahal U et al (2016) Nuclear m(6)A reader YTHDC1 regulates mRNA splicing. Mol Cell 61, 507-519

25. Roundtree IA, Luo GZ, Zhang Z et al (2017) YTHDC1 mediates nuclear export of $\mathrm{N}(6)$-methyladenosine methylated mRNAs. Elife 6, e31311

26. Patil DP, Chen CK, Pickering BF et al (2016) m(6)A RNA methylation promotes XIST-mediated transcriptional repression. Nature 537, 369-373

27. Mao $Y$, Dong L, Liu $X M$ et al (2019) $m(6) A$ in mRNA coding regions promotes translation via the RNA helicase-containing YTHDC2. Nat Commun 10, 5332

28. Alarcon CR, Lee $\mathrm{H}$, Goodarzi $\mathrm{H}$, Halberg $\mathrm{N}$ and Tavazoie SF (2015) N6-methyladenosine marks primary microRNAs for processing. Nature 519, 482-485

29. Huang $H$, Weng $H$, Sun $W$ et al (2018) Recognition of RNA N(6)-methyladenosine by IGF2BP proteins enhances mRNA stability and translation. Nat Cell Biol 20, 285295

30. Wu R, Li A, Sun B et al (2019) A novel m(6)A reader Prrc2a controls oligodendroglial specification and myelination. Cell Res 29, 23-41

31. Dimitrova DG, Teysset L and Carre C (2019) RNA 2'-O-methylation $(\mathrm{Nm})$ modification in human diseases. Genes (Basel) 10, 117

32. Byszewska $M$, Smietanski $M$, Purta $E$ and Bujnicki JM (2014) RNA methyltransferases involved in 5' cap biosynthesis. RNA Biol 11, 1597-1607

33. Dai Q, Moshitch-Moshkovitz S, Han D et al (2017) $\mathrm{Nm}$-seq maps 2'-O-methylation sites in human mRNA with base precision. Nat Methods 14, 695-698

34. Guy MP and Phizicky EM (2015) Conservation of an intricate circuit for crucial modifications of the tRNAPhe anticodon loop in eukaryotes. RNA 21, 61-74

35. Leschziner GD, Coffey AJ, Andrew T et al (2011) Q8IYL2 is a candidate gene for the familial epilepsy syndrome of Partial Epilepsy with Pericentral Spikes (PEPS). Epilepsy Res 96, 109-115

36. Reichow SL, Hamma T, Ferre-D'Amare AR and Varani G (2007) The structure and function of small nucleolar 
ribonucleoproteins. Nucleic Acids Res 35, 1452-1464

37. Belanger F, Stepinski J, Darzynkiewicz E and Pelletier J (2010) Characterization of hMTr1, a human Cap1 2'-O-ribose methyltransferase. J Biol Chem 285, 3303733044

38. Khoddami $V$ and Cairns BR (2013) Identification of direct targets and modified bases of RNA cytosine methyltransferases. Nat Biotechnol 31, 458-464

39. Yang X, Yang Y, Sun BF et al (2017) 5-methylcytosine promotes mRNA export - NSUN2 as the methyltransferase and ALYREF as an $\mathrm{m}(5) \mathrm{C}$ reader. Cell Res 27, 606-625

40. Xing J, Yi J, Cai X et al (2015) NSun2 promotes cell growth via elevating cyclin-dependent kinase 1 translation. Mol Cell Biol 35, 4043-4052

41. Motorin Y, Lyko F and Helm M (2010) 5-methylcytosine in RNA: detection, enzymatic formation and biological functions. Nucleic Acids Res 38, 1415-1430

42. Basanta-Sanchez M, Wang R, Liu Z et al (2017) TET1-mediated oxidation of 5 -formylcytosine ( $5 \mathrm{fC})$ to 5-carboxycytosine (5caC) in RNA. Chembiochem 18, 7276

43. Jobert L, Skjeldam HK, Dalhus B et al (2013) The human base excision repair enzyme SMUG1 directly interacts with DKC1 and contributes to RNA quality control. Mol Cell 49, 339-345

44. Schwartz S, Bernstein DA, Mumbach MR et al (2014) Transcriptome-wide mapping reveals widespread dynamicregulated pseudouridylation of ncRNA and mRNA. Cell 159, 148-162

45. Carlile TM, Rojas-Duran MF, Zinshteyn B, Shin $H$, Bartoli KM and Gilbert WV (2014) Pseudouridine profiling reveals regulated $\mathrm{mRNA}$ pseudouridylation in yeast and human cells. Nature 515, 143-146

46. Duan J, Li L, Lu J, Wang W and Ye K (2009) Structural mechanism of substrate RNA recruitment in H/ACA RNAguided pseudouridine synthase. Mol Cell 34, 427-439

47. Carlile TM, Martinez NM, Schaening C et al (2019) mRNA structure determines modification by pseudouridine synthase 1. Nat Chem Biol 15, 966-974

48. Yoon KJ, Ringeling FR, Vissers C et al (2017) Temporal control of mammalian cortical neurogenesis by $\mathrm{m}(6) \mathrm{A}$ methylation. Cell 171, 877-889 e817

49. Wang $Y$, Li Y, Yue M et al (2018) N(6)-methyladenosine RNA modification regulates embryonic neural stem cell self-renewal through histone modifications. Nat Neurosci 21, 195-206

50. Li Y, Xia L, Tan K et al (2020) N(6)-Methyladenosine co-transcriptionally directs the demethylation of histone H3K9me2. Nat Genet 52, 870-877

51. Yao B, Christian KM, He C, Jin P, Ming GL and Song H (2016) Epigenetic mechanisms in neurogenesis. Nat Rev Neurosci 17, 537-549

52. Li M, Zhao X, Wang $W$ et al (2018) Ythdf2-mediated $\mathrm{m}(6) \mathrm{A}$ mRNA clearance modulates neural development in mice. Genome Biol 19,69

53. Guy MP, Shaw M, Weiner CL et al (2015) Defects in tRNA anticodon loop 2'-O-methylation are implicated in nonsyndromic X-linked intellectual disability due to mutations in FTSJ1. Hum Mutat 36, 1176-1187

54. Higa-Nakamine S, Suzuki T, Uechi T et al (2012) Loss of ribosomal RNA modification causes developmental defects in zebrafish. Nucleic Acids Res 40, 391-398

55. Bouffard S, Dambroise E, Brombin A et al (2018) Fibrillarin is essential for S-phase progression and neuronal differentiation in zebrafish dorsal midbrain and retina. Dev Biol 437, 1-16

56. Cavaille J, Buiting K, Kiefmann M et al (2000) Identification of brain-specific and imprinted small nucleolar RNA genes exhibiting an unusual genomic organization. Proc Natl Acad Sci U S A 97, 14311-14316

57. Peters J (2008) Prader-Willi and snoRNAs. Nat Genet 40, 688-689

58. Rai K, Chidester S, Zavala CV et al (2007) Dnmt2 functions in the cytoplasm to promote liver, brain, and retina development in zebrafish. Genes Dev 21, 261-266

59. Goll MG, Kirpekar F, Maggert KA et al (2006) Methylation of tRNAAsp by the DNA methyltransferase homolog Dnmt2. Science 311, 395-398

60. Blanco S, Dietmann S, Flores JV et al (2014) Aberrant methylation of tRNAs links cellular stress to neuro-developmental disorders. EMBO J 33, 2020-2039

61. Flores JV, Cordero-Espinoza L, Oeztuerk-Winder F et al (2017) Cytosine-5 RNA methylation regulates neural stem cell differentiation and motility. Stem Cell Reports 8, $112-124$

62. Tuorto F, Liebers R, Musch T et al (2012) RNA cytosine methylation by Dnmt2 and NSun2 promotes tRNA stability and protein synthesis. Nat Struct Mol Biol 19, 900905

63. Angelova MT, Dimitrova DG, Dinges N et al (2018) The emerging field of epitranscriptomics in neurodevelopmental and neuronal disorders. Front Bioeng Biotechnol 6, 46

64. Shaheen R, Han L, Faqeih E et al (2016) A homozygous truncating mutation in PUS3 expands the role of tRNA modification in normal cognition. Hum Genet 135, 707713

65. Heiss NS, Bachner D, Salowsky R, Kolb A, Kioschis $P$ and Poustka A (2000) Gene structure and expression of the mouse dyskeratosis congenita gene, $\mathrm{dkc} 1$. Genomics $67,153-163$

66. Xu H, Dzhashiashvili $Y$, Shah A et al (2020) m(6)A mRNA methylation is essential for oligodendrocyte maturation and CNS myelination. Neuron 105, 293-309 e295

67. Chizhikov V and Millen KJ (2003) Development and malformations of the cerebellum in mice. Mol Genet Metab 80, 54-65

68. Wang CX, Cui GS, Liu X et al (2018) METTL3-mediated m6A modification is required for cerebellar development. PLoS Biol 16, e2004880

69. Ma C, Chang M, Lv H et al (2018) RNA m(6)A methylation participates in regulation of postnatal development of the mouse cerebellum. Genome Biol 19,68

70. Ma DK, Bonaguidi MA, Ming GL and Song H (2009) Adult neural stem cells in the mammalian central nervous system. Cell Res 19, 672-682

71. Chen J, Zhang YC, Huang $C$ et al (2019) m(6)A regulates neurogenesis and neuronal development by modulating histone methyltransferase Ezh2. Genomics Proteomics Bioinformatics 17, 154-168 
72. Li L, Zang L, Zhang F et al (2017) Fat mass and obesity-associated (FTO) protein regulates adult neurogenesis. Hum Mol Genet 26, 2398-2411

73. Batool S, Raza H, Zaidi J, Riaz S, Hasan S and Syed NI (2019) Synapse formation: from cellular and molecular mechanisms to neurodevelopmental and neurodegenerative disorders. J Neurophysiol 121, 1381-1397

74. Chang M, Lv H, Zhang W et al (2017) Region-specific RNA m(6)A methylation represents a new layer of control in the gene regulatory network in the mouse brain. Open Biol 7, 170166

75. Engel M, Eggert C, Kaplick PM et al (2018) The role of $\mathrm{m}(6) \mathrm{A} / \mathrm{m}-\mathrm{RNA}$ methylation in stress response regulation. Neuron 99, 389-403 e389

76. Koranda JL, Dore L, Shi H et al (2018) Mettl14 is essential for epitranscriptomic regulation of striatal function and learning. Neuron 99, 283-292 e285

77. Shi H, Zhang X, Weng YL et al (2018) m(6)A facilitates hippocampus-dependent learning and memory through YTHDF1. Nature 563, 249-253

78. Merkurjev D, Hong WT, lida K et al (2018) Synaptic $\mathrm{N}(6)$-methyladenosine $(\mathrm{m}(6) \mathrm{A})$ epitranscriptome reveals functional partitioning of localized transcripts. Nat Neurosci 21, 1004-1014

79. Zhang Z, Wang M, Xie D et al (2018) METTL3-mediated $\mathrm{N}(6)$-methyladenosine mRNA modification enhances long-term memory consolidation. Cell Res 28, 1050-1061

80. Hou Y, Dan X, Babbar M et al (2019) Ageing as a risk factor for neurodegenerative disease. Nat Rev Neurol $15,565-581$

81. Casella G, Tsitsipatis D, Abdelmohsen $K$ and Gorospe $M$ (2019) mRNA methylation in cell senescence. Wiley Interdiscip Rev RNA 10, e1547

82. Min KW, Zealy RW, Davila $S$ et al (2018) Profiling of m6A RNA modifications identified an age-associated regulation of AGO2 mRNA stability. Aging Cell 17, e12753

83. Lee MY, Leonardi A, Begley TJ and Melendez JA (2020) Loss of epitranscriptomic control of selenocysteine utilization engages senescence and mitochondrial reprogramming. Redox Biol 28, 101375

84. Weng YL, Wang X, An R et al (2018) Epitranscriptomic $\mathrm{m}(6)$ A regulation of axon regeneration in the adult mammalian nervous system. Neuron 97, 313-325 e316

85. Cumming TB and Brodtmann A (2011) Can stroke cause neurodegenerative dementia? Int J Stroke 6, 416-424

86. Chokkalla AK, Mehta SL, Kim T, Chelluboina B, Kim J and Vemuganti R (2019) Transient focal ischemia significantly alters the $\mathrm{m}(6) \mathrm{A}$ epitranscriptomic tagging of RNAs in the brain. Stroke 50, 2912-2921

87. Fan L, Mao C, Hu X et al (2019) New insights into the pathogenesis of Alzheimer's disease. Front Neurol 10, 1312

88. Keller L, Xu W, Wang HX, Winblad B, Fratiglioni L and Graff C (2011) The obesity related gene, FTO, interacts with APOE, and is associated with Alzheimer's disease risk: a prospective cohort study. J Alzheimers Dis 23, 461-469

89. Reitz C, Tosto G, Mayeux R, Luchsinger JA, Group $\mathrm{N}$-LNFS and Alzheimer's disease neuroimaging I (2012) Genetic variants in the fat and obesity associated (FTO) gene and risk of Alzheimer's disease. PLoS One 7, e50354

90. Li H, Ren Y, Mao K et al (2018) FTO is involved in Alzheimer's disease by targeting TSC1-mTOR-Tau signaling. Biochem Biophys Res Commun 498, 234-239

91. Liu X, Meng P, Yang G, Zhang M, Peng S and Zhai MZ (2020) Genome-wide identification and transcript profiles of walnut heat stress transcription factor involved in abiotic stress. BMC Genomics 21, 474

92. Westmark CJ, Maloney B, Alisch RS, Sokol DK and Lahiri DK (2020) FMRP regulates the nuclear export of Adam9 and Psen 1 mRNAs: secondary analysis of an N(6)-methyladenosine dataset. Sci Rep 10, 10781

93. Boza-Serrano A, Yang Y, Paulus A and Deierborg T (2018) Innate immune alterations are elicited in microglial cells before plaque deposition in the Alzheimer's disease mouse model 5xFAD. Sci Rep 8, 1550

94. Balestrino R and Schapira AHV (2020) Parkinson disease. Eur J Neurol 27, 27-42

95. Chen X, Yu C, Guo M et al (2019) Down-regulation of $\mathrm{m} 6 \mathrm{~A}$ mRNA methylation is involved in dopaminergic neuronal death. ACS Chem Neurosci 10, 2355-2363

96. Hess ME, Hess S, Meyer KD et al (2013) The fat mass and obesity associated gene (Fto) regulates activity of the dopaminergic midbrain circuitry. Nat Neurosci 16, 1042-1048

97. Peng S, Xiao W, Ju D et al (2019) Identification of entacapone as a chemical inhibitor of FTO mediating metabolic regulation through FOXO1. Sci Transl Med 11, eaau7116

98. Vissers LE, Gilissen C and Veltman JA (2016) Genetic studies in intellectual disability and related disorders. Nat Rev Genet 17, 9-18

99. Iwase S, Berube NG, Zhou Z et al (2017) Epigenetic etiology of intellectual disability. J Neurosci 37, 10773-10782

100. Zhang F, Kang Y, Wang M et al (2018) Fragile X mental retardation protein modulates the stability of its m6A-marked messenger RNA targets. Hum Mol Genet 27, 39363950

101. Ignatova $\mathrm{V}$, Stolz $P$, Kaiser $S$ et al (2020) The rRNA $\mathrm{m}(6) \mathrm{A}$ methyltransferase METTL5 is involved in pluripotency and developmental programs. Genes Dev 34, 715729

102. Richard EM, Polla DL, Assir MZ et al (2019) Bi-allelic variants in METTL5 cause autosomal-recessive intellectual disability and microcephaly. Am J Hum Genet 105 869-878

103. de Brouwer APM, Abou Jamra R, Kortel N et al (2018) Variants in PUS7 cause intellectual disability with speech delay, microcephaly, short stature, and aggressive behavior. Am J Hum Genet 103, 1045-1052

104. Bykhovskaya $\mathrm{Y}$, Casas K, Mengesha E, Inbal A and Fischel-Ghodsian N (2004) Missense mutation in pseudouridine synthase 1 (PUS1) causes mitochondrial myopathy and sideroblastic anemia (MLASA). Am J Hum Genet 74, 1303-1308

105. Cao M, Dona M, Valentino ML et al (2016) Clinical and molecular study in a long-surviving patient with MLASA syndrome due to novel PUS1 mutations. Neurogenetics $17,65-70$

106. Abbasi-Moheb L, Mertel S, Gonsior M et al (2012) Mu- 
tations in NSUN2 cause autosomal-recessive intellectual disability. Am J Hum Genet 90, 847-855

107. Martinez FJ, Lee JH, Lee JE et al (2012) Whole exome sequencing identifies a splicing mutation in NSUN2 as a cause of a Dubowitz-like syndrome. J Med Genet 49, 380-385

108. Khan MA, Rafiq MA, Noor A et al (2012) Mutation in NSUN2, which encodes an RNA methyltransferase, causes autosomal-recessive intellectual disability. Am J Hum Genet 90, 856-863

109. Willems $P$, Vits L, Buntinx I, Raeymaekers $P$, Van Broeckhoven C and Ceulemans B (1993) Localization of a gene responsible for nonspecific mental retardation (MRX9) to the pericentromeric region of the $X$ chromosome. Genomics 18, 290-294

110. Hamel BC, Smits AP, van den Helm B et al (1999) Four families (MRX43, MRX44, MRX45, MRX52) with nonspecific X-linked mental retardation: clinical and psychometric data and results of linkage analysis. Am J Med Genet 85, 290-304

111. Dai L, Xing L, Gong P et al (2008) Positive association of the FTSJ1 gene polymorphisms with nonsyndromic Xlinked mental retardation in young Chinese male subjects. J Hum Genet 53, 592-597

112. Wang R, Lei T, Fu F et al (2019) Application of chromosome microarray analysis in patients with unexplained developmental delay/intellectual disability in South China. Pediatr Neonatol 60, 35-42

113. Giorda R, Bonaglia MC, Beri S et al (2009) Complex segmental duplications mediate a recurrent $\operatorname{dup}(\mathrm{X})(\mathrm{p} 11$. 22-p11.23) associated with mental retardation, speech delay, and EEG anomalies in males and females. Am J Hum Genet 85, 394-400

114. Zhang X, Wang F, Wang Z et al (2020) ALKBH5 promotes the proliferation of renal cell carcinoma by regulating $\mathrm{AURKB}$ expression in an $\mathrm{m}(6) \mathrm{A}$-dependent manner. Ann Transl Med 8, 646

115. Jensen LR, Garrett L, Holter SM et al (2019) A mouse model for intellectual disability caused by mutations in the X-linked 2'Omethyltransferase Ftsj1 gene. Biochim Biophys Acta Mol Basis Dis 1865, 2083-2093

116. Bai L, Tang Q, Zou Z et al (2018) m6A demethylase FTO regulates dopaminergic neurotransmission deficits caused by arsenite. Toxicol Sci 165, 431-446

117. Choudhry Z, Sengupta SM, Grizenko N et al (2013) Association between obesity-related gene FTO and ADHD. Obesity (Silver Spring) 21, E738-744

118. Oldmeadow C, Mossman D, Evans TJ et al (2014) Combined analysis of exon splicing and genome wide polymorphism data predict schizophrenia risk loci. J Psychiatr Res 52, 44-49

119. Yoon KJ, Ming GL and Song H (2018) Epitranscriptomes in the adult mammalian brain: dynamic changes regulate behavior. Neuron 99, 243-245

120. Barbon A and Magri C (2020) RNA editing and modifications in mood disorders. Genes (Basel) 11, 872

121. Du T, Rao S, Wu L et al (2015) An association study of the m6A genes with major depressive disorder in Chinese Han population. J Affect Disord 183, 279-286

122. Bian J, Zhuo Z, Zhu J et al (2020) Association between
METTL3 gene polymorphisms and neuroblastoma susceptibility: A nine-centre case-control study. J Cell Mol Med 24, 9280-9286

123. Zhuo Z, Lu H, Zhu J et al (2020) METTL14 gene polymorphisms confer neuroblastoma susceptibility: an eightcenter case-control study. Mol Ther Nucleic Acids 22, $17-26$

124. Cheng J, Xu L, Deng L et al (2020) RNA N(6)-methyladenosine modification is required for miR-98/MYCN axismediated inhibition of neuroblastoma progression. Sci Rep 10, 13624

125. Wang Z, Cheng $H, X u ~ H, Y u X$ and Sui D (2020) A five-gene signature derived from $\mathrm{m} 6 \mathrm{~A}$ regulators to improve prognosis prediction of neuroblastoma. Cancer Biomark 28, 275-284

126. Louis DN, Ohgaki H, Wiestler OD et al (2007) The 2007 WHO classification of tumours of the central nervous system. Acta Neuropathol 114, 97-109

127. Stupp R, Roila F and Group EGW (2009) Malignant glioma: ESMO clinical recommendations for diagnosis, treatment and follow-up. Ann Oncol 20 Suppl 4, $126-128$

128. Xi Z, Xue Y, Zheng J, Liu X, Ma J and Liu Y (2016) WTAP expression predicts poor prognosis in malignant glioma patients. J Mol Neurosci 60, 131-136

129. Sundar SJ, Hsieh JK, Manjila S, Lathia JD and Sloan A (2014) The role of cancer stem cells in glioblastoma. Neurosurg Focus 37, E6

130. Cui Q, Shi H, Ye P et al (2017) m(6)A RNA methylation regulates the self-renewal and tumorigenesis of glioblastoma stem cells. Cell Rep 18, 2622-2634

131. Zhang S, Zhao BS, Zhou A et al (2017) m(6)A demethylase ALKBH5 maintains tumorigenicity of glioblastoma stem-like cells by sustaining FOXM1 expression and cell proliferation program. Cancer Cell 31, 591-606 e596

132. Visvanathan A, Patil V, Arora A et al (2018) Essential role of METTL3-mediated $\mathrm{m}(6)$ A modification in glioma stem-like cells maintenance and radioresistance. Oncogene $37,522-533$

133. Zang $L$, Kondengaden $S M$, Che F, Wang $L$ and Heng $X$ (2018) Potential epigenetic-based therapeutic targets for glioma. Front Mol Neurosci 11, 408

134. Ge L, Zhang N, Chen Z et al (2020) Level of N6methyladenosine in peripheral blood RNA: a novel predictive biomarker for gastric cancer. Clin Chem 66, 342-351

135. Strick A, von Hagen F, Gundert L et al (2020) The N(6)methyladenosine $(\mathrm{m}(6) \mathrm{A})$ erasers alkylation repair homologue $5(\mathrm{ALKBH} 5)$ and fat mass and obesity-associated protein (FTO) are prognostic biomarkers in patients with clear cell renal carcinoma. BJU Int 125, 617-624

136. Wang W, Li J, Lin F, Guo J and Zhao J (2020) Identification of N(6)-methyladenosine-related IncRNAs for patients with primary glioblastoma. Neurosurg Rev [Online ahead of print]

137. Tu Z, Wu L, Wang P et al (2020) N6-methylandenosine-related IncRNAs are potential biomarkers for predicting the overall survival of lower-grade glioma patients. Front Cell Dev Biol 8, 642

138. Xiao L, Li X, Mu Z et al (2020) FTO inhibition enhances 
the anti-tumor effect of temozolomide by targeting MYCmiR-155/23a cluster-MXI1 feedback circuit in glioma. Cancer Res 80, 3945-3958

139. Malacrida A, Rivara M, Di Domizio A et al (2020) 3D proteome-wide scale screening and activity evaluation of a new ALKBH5 inhibitor in U87 glioblastoma cell line. Bioorg Med Chem 28, 115300
140. Garcia-Campos MA, Edelheit S, Toth $U$ et al (2019) Deciphering the "m(6)A code" via antibody-independent quantitative profiling. Cell 178, 731-747 e716

141. Sas-Chen A, Thomas JM, Matzov D et al (2020) Dynamic RNA acetylation revealed by quantitative cross-evolutionary mapping. Nature 583, 638-643 